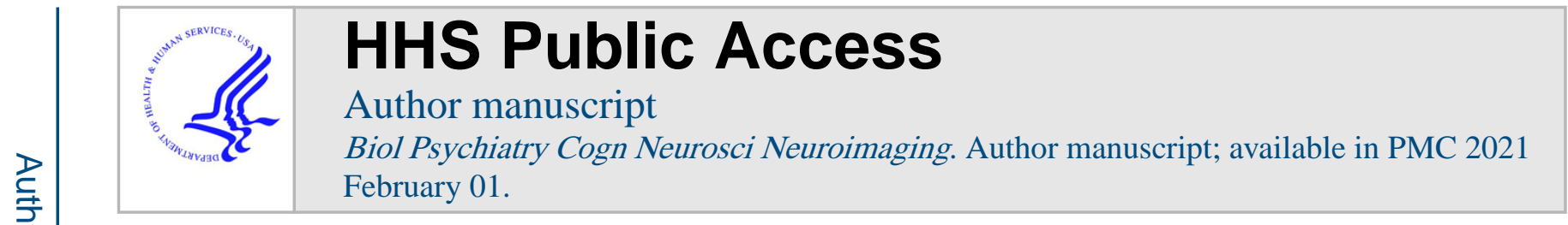

Published in final edited form as:

Biol Psychiatry Cogn Neurosci Neuroimaging. 2020 February ; 5(2): 231-238. doi:10.1016/

j.bpsc.2019.10.014.

\title{
Duration of Untreated Psychosis Correlates with Brain Connectivity and Morphology in Medication-Naïve Patients with First Episode Psychosis
}

\author{
Jose O. Maximo, Ph.D. ${ }^{1}$, Eric A. Nelson, M.A. ${ }^{2}$, William P. Armstrong, M.S. ${ }^{1}$, Nina V. \\ Kraguljac, M.D. ${ }^{1}$, Adrienne C. Lahti, M.D. ${ }^{1, *}$ \\ ${ }^{1}$ Department of Psychiatry and Behavioral Neurobiology, University of Alabama at Birmingham \\ ${ }^{2}$ Department of Psychology, University of Alabama at Birmingham
}

\section{Abstract}

Background-In the United States, the average duration of untreated psychosis (DUP) is 21 months and it remains unknown how longer DUP may affect brain functioning in antipsychoticnaïve patients with first episode psychosis (FEP). Our objective was to determine the effects of DUP on functional connectivity and brain morphology measured with resting state functional and structural MRI.

Methods-Medication-naïve FEP patients were referred from various clinical settings. After accounting for exclusion criteria, attrition, and data quality, final analyses included 55 patients (35M/20F; mean age of 24.18 years). FEP patients were subjected to a 16 -week trial of risperidone, a commonly used antipsychotic drug. Treatment response was calculated as change in the BPRS psychosis subscale between baseline and 16 weeks. Resting state functional connectivity MRI and brain morphology (surface area and cortical thickness) were assessed.

\footnotetext{
*Corresponding author: Adrienne C. Lahti, M.D., Department of Psychiatry and Behavioral Neurobiology, University of Alabama at Birmingham, SC 501, $15303^{\text {rd }}$ Ave South, Birmingham, AL 35294-0017, Phone: (205) 996-6776, Fax: (205) 975-4879, alahti@uabmc.edu.

Author Contributions: Dr. Lahti had full access to all of the data in the study and takes responsibility for the integrity of the data and the accuracy of the data analysis.

Study concept and design: Lahti.

Acquisition of data: Nelson, Armstrong, Kraguljac.

Analysis and interpretation of data: All authors.

Drafting of the manuscript: Maximo, Kraguljac, Lahti.

Statistical analysis: Maximo.

Obtained funding: Lahti.

Administrative, technical, or material support: Lahti.

Study supervision: Lahti.

Conflict of Interest: All authors report no relevant biomedical financial interests or potential conflicts of interest.

Clinical Trial Registration:

- Trajectories of Treatment Response as Window into the Heterogeneity of Psychosis: A Longitudinal Multimodal Imaging Study, NCT03442101 https://clinicaltrials.gov/ct2/show/NCT03442101.

- Glutamate, Brain Connectivity and Duration of Untreated Psychosis (DUP), NCT02034253 https://clinicaltrials.gov/ct2/show/ NCT02034253

Publisher's Disclaimer: This is a PDF file of an unedited manuscript that has been accepted for publication. As a service to our customers we are providing this early version of the manuscript. The manuscript will undergo copyediting, typesetting, and review of the resulting proof before it is published in its final form. Please note that during the production process errors may be discovered which could affect the content, and all legal disclaimers that apply to the journal pertain.
} 
Results-Longer DUP was associated with worse treatment response and reduced functional connectivity - more specifically in default, salience, and executive networks. Moreover, longer DUP was associated with reduced surface area in salience and executive networks and with increased cortical thickness in default mode and salience networks. When the functional connectivity of the default mode network was added as a mediator, the relationship between DUP and treatment response was no longer significant.

Conclusions-Our data suggest that several neurobiological alterations in the form of reduced functional connectivity and surface area and increased cortical thickness underpin the effect of prolonged DUP.

\section{Keywords}

Duration of untreated psychosis; resting state; functional connectivity; morphology; brain networks; treatment response

\section{INTRODUCTION}

Meta-analyses (1-3) have consistently identified an association between the duration of untreated psychosis (DUP), the duration between the onset of positive symptoms and treatment, and clinical outcomes $(1,4,5)$. This relationship is found across various lengths of follow-up periods, suggesting that DUP influences the long term course of the illness (6). Given that in the United States the average DUP is 74 weeks (7), the National Institute of Mental Health (NIMH) has deemed it critical to identify strategies to reduce the DUP (8) in an effort to alleviate the overall disease burden in psychosis spectrum patients.

Importantly, active psychosis might adversely affect the brain (9), possibly via $N$-methyl-Daspartate (NMDA) receptor hypofunctioning (10-12), increased dopaminergic activity (13), or persistent catecholaminergic and hypothalamic pituitary adrenal axis activity (14). Several studies have attempted to characterize the effects of DUP on the brain with non-invasive brain imaging techniques including T1 weighted imaging (15-19), diffusion weighted imaging (20), functional MRI $(21,22)$ and MR Spectroscopy (23). While not all studies have detected a direct relationship between DUP and brain structure or function (See review by 24), methodological limitations such as prior exposure to antipsychotic drugs (APD) and variable illness durations at the time of assessment may have disguised existing associations (25-28). To address these limitations, we designed a prospective multimodal imaging study with the goal to investigate the impact of the duration of untreated psychosis on brain structure and function in medication-naive first episode psychosis (FEP) patients.

Connectome analyses have provided abundant data suggesting that three large-scale brain networks deemed critical for higher-order cognitive processes, the default mode (DMN), salience (SN), and central executive networks (CEN) (29), are affected in the illness. Importantly, deficits are observed in both functional connectivity (FC) and cortical morphology $(30,31)$, suggesting a possible relationship between functional and structural alterations in these brain networks. The goal of this longitudinal multimodal imaging study was two-fold: one, to examine the relationship between the DUP and the three-network FC and cortical morphology in medication-naïve FEP; and second, to evaluate their contribution 
to eventual treatment response following APD treatment. Because it can take up to 16 weeks for FEP patients to respond (32), we measured treatment response over this period. We hypothesized that longer DUP would be associated with reduced functional connectivity (FC) and altered cortical morphology, as well as with poor treatment response. We further hypothesized that these functional and morphological alterations would mediate the link between DUP and treatment response. To our knowledge, this is the first study to examine DUP in medication-naïve FEP from a multimodal imaging approach.

\section{METHODS AND MATERIALS}

\section{Participants}

We screened 169 medication-naïve FEP, recruited from outpatient clinics, inpatient units and the emergency room at the University of Alabama at Birmingham (UAB). Studies were approved by the University of Alabama at Birmingham Institutional Review Board, and written informed consent was obtained before enrollment (FEP patients had to be deemed competent to provide consent). Exclusion criteria were major neurological or medical conditions, history of significant head trauma, substance use disorders (excluding nicotine and cannabis) within 1 month of imaging, more than five days of lifetime antipsychotic exposure, pregnancy or breastfeeding, and MRI contraindications. One hundred and three medication-naïve FEP did not meet inclusion criteria and 7 dropped before start of antipsychotic trial which left us with a sample size of 59. This number dropped to $\mathrm{N}=55$ after quality control (see Data Preprocessing).

Scans were obtained prior to treatment. Patients underwent a 16-week treatment with risperidone using a flexible dosing regimen. Risperidone was started at $1-2 \mathrm{mg}$ and titrated in 1-2mg increments; dosing was based on therapeutic and side effects. Use of concomitant medications was permitted as clinically indicated and were prescribed after the MRI session. Twenty four medication-naïve FEP were prescribed the following during the trial: amphetamine (1), benztropine (16), sertraline (7), escitalopram (1), lithium (1), trazodone (2), lorazepam (1), valproic acid (1), and bupropion (1). Seven patients were under more than one medication. Compliance was monitored with pill counts at each visit. The interval between scanning and antipsychotic initiation was $<24 \mathrm{hrs}$.

\section{Clinical Assessment}

Consensus diagnoses were made according to DMS-V criteria by two board certified psychiatrists from all historical and direct assessment information available (ACL and NVK). Determination of DUP was based on information provided by the patient and caregivers during screening as well as any time during the 16-week trial period. The Brief Psychiatric Rating Scale (BPRS) and Repeatable Battery for the Assessment of Neuropsychological Status (RBANS) were used to assess symptom severity and cognition $(33,34)$. Treatment response (TR) was defined as the percent change on the BPRS psychosis (BPRS+) subscale from baseline to 16 weeks of risperidone where a greater percentage indicates a greater reduction in positive symptoms $\left[\left(\mathrm{BPRS}+{ }_{\text {Baseline }}-\mathrm{BPRS}+{ }_{\text {Week }}{ }_{16}\right) /\right.$ $\left(\right.$ BPRS $\left.\left._{\text {Baseline }}\right)\right] \times(-100)$. TR data were available for 41 medication-naïve FEP. 


\section{Data Acquisition}

All imaging was performed on a 3T whole-body Siemens MAGNETOM Prisma MRI scanner equipped with a 20-channel head coil. A high-resolution 1 T1-weighted structural scan was acquired for anatomical reference and morphological analyses (MPRAGE: TR = $2400 \mathrm{~ms} ; \mathrm{TE}=2.22 \mathrm{~ms}$; inversion time $=1000 \mathrm{~ms}$; flip angle $=8^{\circ}$; GRAPPA factor $=2$; voxel size $\left.=0.8 \mathrm{~mm}^{3}\right)$. A T2-weighted image was also obtained $(\mathrm{TR}=3200 \mathrm{~ms}$; TE $=563.0 \mathrm{~ms}$; flip angle $=8^{\circ}$; GRAPPA factor $=2,208$ slices, voxel size $\left.=0.8 \mathrm{~mm}^{3}\right)$. Resting state functional MRI (fMRI) data was acquired in opposing phase encoding directions (A>P and P> A; TR $=1550 \mathrm{~ms} ; \mathrm{TE}=37.80 \mathrm{~ms} ;$ flip angle $=71^{\circ}, \mathrm{FOV}=104 \mathrm{~mm}^{2} ;$ multi-band acceleration factor $=4$; voxel size $=2 \mathrm{~mm}^{3} ; 225$ volumes, and 72 axial slices). Subjects were instructed to keep their eyes open and let their mind wander.

\section{Data Preprocessing}

Morphological Data-Structural images were processed and analyzed using Freesurfer $6.0(35,36)$ using standard preprocessing steps (http://surfer.nmr.mgh.harvard.edu/). Briefly, $\mathrm{T} 1$ and $\mathrm{T} 2$ weighted images were skull stripped (37), segmented and parceled into units based on gyral and sulcal structure in FSL, resulting in estimates for volume, cortical thickness, and surface area (38). Data quality was assessed with the Qoala-T Tool, which uses a supervised-learning model to reduce rater bias and misclassification (39). Scans with a Qoala-T score below 70\% were visually inspected for accuracy in pial and white matter surface registration. Two structural scans were removed from final analysis due to irreparable artifacts resulting in 53 medication-naïve FEP for morphometric analyses.

Resting state fMRI Data-Data were analyzed using the CONN toolbox version 18a (40). After discarding the first 10 volumes of each scan allowing for signal equilibration, field inhomogeneities were corrected in FSL's topup, and merged resulting in a single 4D image of 430 total volumes (41). Functional images were then slice-timing and motioncorrected using rigid-body realignment, co-registered to the structural image, normalized to Montreal Neurological Institute (MNI) space, bandpass filtered $(0.008<f<0.08 \mathrm{~Hz})$, and spatially smoothed with a 4-mm full width at half maximum Gaussian (FWHM) kernel.

Framewise displacement (FD) and percentage of censored data were then calculated (42). Motion outliers as detected by the artifact detection (ART) toolbox were censored (composite volume-to-volume motion $>0.9 \mathrm{~mm}$ and intensity $>5 \mathrm{SDs}$ ), and the six motion parameters derived from rigid-body realignment and their derivatives, as well as the first component time series derived from CSF and white matter using aCompCor and corresponding derivatives, were regressed out from the signal.

After excluding patients who dropped out from the study, did not have a baseline MRI scan (1), had irreparable artifacts (1), or had excessive head motion (2), our final sample included 55 patients.

\section{Statistical Analyses}

For morphometric analyses (volume, cortical thickness, and surface), labels of the DMN, SN, and CEN defined from the CorticalParcellation_Yeo2011 (43) were projected onto each 
subject. Measures were extracted from right and left hemispheres labels and entered into partial correlations with DUP (log transformed to account for non-normal distribution of data) while controlling for age and estimated Total Intracranial Volume (eTIV). Since sex and eTIV were highly correlated, we only controlled for the latter.

For FC analyses, four CONN toolbox-based regions of interest (ROIs) were used: DMN (posterior cingulate cortex, PCC), SN (right anterior insula, RAI), and CEN (left and right posterior parietal cortex, L/RPPC). We then created individual whole-brain z-transformed correlation maps for each ROI to each voxel of the brain. Second-level analyses were performed for each correlation map using separate general linear models with DUP with age, sex, and FD as covariates. All analyses were corrected using voxel $\left(p_{\text {uncorrected }}<0.01\right)$ and cluster level correction $\left(p_{\mathrm{FDR}}<0.05\right)$.

Finally, a mediation analysis was performed to examine whether brain morphology and connectivity mediated the relationship between DUP and TR. A factor analysis via principal component analysis was performed on the combined FC and morphological results (Figure 1) to reduce the data, and was examined using a varimax rotation on SPSS. According to Judd and Kenny (44), we tested whether: a) the effect of DUP on TR is significant; b) a significant relationship between DUP and brain data exits; c) the relationship between brain data and TR is significant; and d) the direct effect of DUP on TR adjusted for brain data is not significant.

\section{RESULTS}

\section{Demographics and Clinical Data}

Demographic data are summarized in Table 1. The average DUP was 19.65 months (SD = 39.42 months), and the median was 6 months. Age and sex were not correlated with DUP. Longer DUP prior to treatment was associated with worse TR after controlling for age and gender $(b=-0.376, p=0.019)$. RBANS scores were not correlated with DUP.

\section{Brain Functional Connectivity and Morphology}

Results for DMN revealed significant clusters of negative correlations between DUP and baseline posterior cingulate cortex FC in bilateral medial and pre/postcentral regions ( $p_{\text {FDR }}$ $<0.05$, Table 2). On the other hand, cortical thickness of the right hemisphere was positively correlated with DUP $(r=0.25, p=0.04$, Figure 1A and Table 3$)$. For the SN, significant clusters showing negative correlations between DUP and baseline right anterior insula FC were found in bilateral temporal regions, left middle frontal gyrus, right medial prefrontal, and right precentral gyrus $\left(p_{\mathrm{FDR}}<0.05\right.$, Table 2$)$. Similarly, a negative and positive correlation between left hemisphere surface area $(r=-0.27, p=0.03)$ and right hemisphere cortical thickness $(r=0.28, p=0.03)$ with DUP were found respectively (Figure 1B and Table 3). Lastly, for CEN, significant clusters showing a negative correlation between DUP and baseline right posterior parietal cortex FC were found in left precentral, right angular, and ventral temporal regions; whereas a cluster showing a positive correlation was found in right middle gyrus and when using the left posterior parietal cortex seed, one cluster showing a negative correlation between DUP and baseline connectivity was found in the 
right angular gyrus $\left(p_{\mathrm{FDR}}<0.05\right.$, Table 2$)$. Similarly, negative correlations between left and right hemisphere surface were found with DUP $(r=-0.28, p=0.02$ and $r=-0.25, p=0.04$ respectively; Figure 1C and Table 3). No significant correlations emerged between DUP and cortical volume.

\section{Mediation Analysis}

A total of 6 factors (out of 22 total) had eigenvalues greater than 1.0, cumulative accounting for $77 \%$ of the total variance. The factor with the highest explained variance (34\%) included loadings from DMN and SN after a varimax rotation solution; however, it did not meet the requirements for being a potential mediator (step c). As an exploratory approach, we tested each DMN and SN FC data for potential mediation given that the factor loadings came mostly from these networks. We found that FC of the DMN that correlated with DUP (clusters from Figure 1A) met all requirements for being a potential mediator, but not $\mathrm{FC}$ of the SN (44). When FC of the DMN was included as a mediator in the model, the direct path from DUP to TR ( $b=-0.376, p=0.019)$ was no longer significant $(b=-0.396, p=0.072$ ), which indicated that DUP exerted its effect on TR through FC of the DMN (Figure 2). This analysis showed a significant mediated effect using a Sobel test $(z=-1.94, p=0.03)$.

\section{DISCUSSION}

To our knowledge, we are the first to simultaneously investigate brain function and structure in three major neural networks in antipsychotic-naive FEP in order to understand the neural substrates of the relationship between DUP and clinical outcomes. We demonstrated that longer DUP was associated with reduced FC in all three networks, and a single cluster of increased FC in the CEN network. Furthermore, we found that greater DUP was associated with reduced surface area in the SN and CEN, and reported positive correlations between cortical thickness and DUP in the SN and DMN. Importantly, our data empirically support that DMN connectivity mediates the relationship between DUP and treatment response, implicating brain network connectivity as a neurobiological underpinning of the relationship between longer DUP and poorer clinical outcomes.

Our findings are consistent with the only two studies that examined FC in relation to DUP $(21,22)$. Sarpal, Robinson (22) reported correlations between corticostriatal connectivity and DUP in early phase schizophrenia with less than two years of antipsychotic exposure. Similar to us, they found that corticostriatal connectivity mediated the relationship between DUP and treatment response. More recently, Manivannan, Foran (21) reported correlations between task-based fMRI using a visuospatial working memory task with DUP in FEP (22 medication naïve and 12 with prior APD exposure).

We observed negative correlations between surface area of SN and CEN, and positive ones between cortical thickness of DMN and SN with DUP. Previous studies reported a set of mixed results where some have found a direct link between brain morphology and DUP (1618 ) and others have failed to do so $(19,24)$. However, the majority of these studies only examined volume. Because cortical thickness and surface area have distinct developmental trajectories and genetic influences, they index different biological entities $(45,46)$. Surface area is a loose representation of the number of minicolumns running perpendicular to the 
surface of the brain, whereas cortical thickness reflects the size, density, and arrangement of neurons, neuroglia, and nerve fibers (47). Reduction in neuropil and GABAergic interneurons (which are found in cortical minicolumns) previously found in schizophrenia in postmortem studies may help explain reduction in surface area in frontal and temporal areas (48-51). Similarly, increased cortical thickness in medial prefrontal and insular regions may be associated with brain inflammation, which has been found in the early stages of schizophrenia and may be the result of global and focal reduction, hypodensities, and deficits in myelin and activated microglia (52-56). Overall, reduction of surface area and increased cortical thickness as a function of DUP strongly point to alterations in the functional organization of the neocortex with longer DUP.

While these findings suggest that one or several pathophysiologic processes underlie the DUP, the mechanism that may cause these alterations is currently unknown, although different mechanisms have been proposed $(10,15)$. Our principal component analysis of all significant brain morphology and functional connectivity matrix revealed a factor explaining $34 \%$ of the variance that is comprised of FC only, indicating its greater contribution to the association with the DUP.

Shorter DUP associated with better outcome implicates a process by which APDs attenuate the pathophysiological process underlying the DUP. Our results indicate that DMN connectivity positively predicted TR and mediated the relationship between DUP and TR. Links between the DMN and dopamine (DA) activity exist. Modulation of the DMN network has been achieved with various dopaminergic compounds (57-60), and is associated with striatal DA transporter activity (61), and genetic variation of the catechol-Omethyltransferase (COMT) enzyme (62). We previously reported that the FC between the ventral tegmental area, the origin of the mesocorticolimbic DA projections, and the DMN predicted TR $(27,28,63)$. In addition, a recent study that evaluated both structural and functional predictors of TR identified DMN connectivity as the single most important predictor of response (64). Together these results indicate an important role of the DMN FC in treatment response, as well as being a neurobiological underpinning of the relationship between DUP and treatment response.

Like others (65) (4), we did not find an association between DUP and cognitive deficits measured with the RBANS. This may be because cognitive deficits are already established at the onset of psychosis and do not worsen in the early stage of illness, or that more finegrained measures of cognition are needed. Additionally, the heterogeneity within FEP, which show different levels of cognitive impairment could potentially mask this association (66).

There are several strengths and limitations to our study. We enrolled a sample of medicationnaïve first-episode psychosis patients at first treatment contact in our medical center; the vast majority of them had never been exposed to antipsychotic medications before the first scan allowing us to study psychosis with negligible confound of medications on measurements, although medication before scanning could affect connectivity. We chose not to exclude patients with cannabis use, approximately $30 \%$ of our sample tested positive for cannabis at study entry. Though exposure to cannabis may affect brain structure and function, it is one of the major risk factors for developing a psychotic illness and therefore highly clinically 
relevant. Only including patients without a history of cannabis use would have inadvertently biased our sample and limited the generalizability of our data. We also obtained DUP from patients and their next of kin in a retrospective manner. A quantitative review comparing methods of gauging DUP concluded that clinical interviews are no less reliable than standardized assessment tools, but that the definition of treatment onset as first-ever antipsychotic medication prescription or first hospitalization may have greater validity compared to other methods such as first adequate response to treatment (67).

To summarize, we simultaneously investigated brain function and structure in three major neural networks in medication-naïve FEP and found that FC of the DMN mediated the relationship between DUP and treatment response, suggesting a neurobiological mechanism underlying this phenomenon. Overall, our findings add knowledge to the emerging theme of the NIMH of further understanding the neural correlates of DUP in psychopathology. Finally, these findings highlight the importance of reducing DUP and initiation of treatment as soon as possible to mitigate the detrimental effects of psychosis on long-term clinical outcomes.

\section{Acknowledgements}

Special thanks to the patients and their families.

Funding: This work was supported by the National Institutes of Health (R01MH102951 and R01MH113800).

Role of the Sponsor: The funding agency had no role in the design and conduct of the study; collection, management, analysis, and interpretation of the data; and preparation, review, or approval of the manuscript; and decision to submit the manuscript for publication.

\section{References}

1. Perkins DO, Gu H, Boteva K, Lieberman JA. Relationship between duration of untreated psychosis and outcome in first-episode schizophrenia: a critical review and meta-analysis. The American journal of psychiatry. 2005;162:1785-1804. [PubMed: 16199825]

2. Boonstra N, Klaassen R, Sytema S, Marshall M, De Haan L, Wunderink L, Wiersma D. Duration of untreated psychosis and negative symptoms--a systematic review and meta-analysis of individual patient data. Schizophrenia research. 2012;142:12-19. [PubMed: 23025994]

3. Farooq S, Large M, Nielssen O, Waheed W. The relationship between the duration of untreated psychosis and outcome in low-and-middle income countries: a systematic review and meta analysis. Schizophrenia research. 2009;109:15-23. [PubMed: 19233621]

4. Goldberg TE, Burdick KE, McCormack J, Napolitano B, Patel RC, Sevy SM, Goldman R, Lencz T, Malhotra AK, Kane JM, Robinson DG. Lack of an inverse relationship between duration of untreated psychosis and cognitive function in first episode schizophrenia. Schizophr Res. 2009;107:262-266. [PubMed: 19042105]

5. Ho BC, Alicata D, Ward J, Moser DJ, O’Leary DS, Arndt S, Andreasen NC. Untreated initial psychosis: relation to cognitive deficits and brain morphology in first-episode schizophrenia. The American journal of psychiatry. 2003;160:142-148. [PubMed: 12505813]

6. Perkins DO. Review: longer duration of untreated psychosis is associated with worse outcome in people with first episode psychosis. Evid Based Ment Health. 2006;9:36. [PubMed: 16638885]

7. Kane JM, Robinson DG, Schooler NR, Mueser KT, Penn DL, Rosenheck RA, Addington J, Brunette MF, Correll CU, Estroff SE, Marcy P, Robinson J, Meyer-Kalos PS, Gottlieb JD, Glynn SM, Lynde DW, Pipes R, Kurian BT, Miller AL, Azrin ST, Goldstein AB, Severe JB, Lin H, Sint KJ, John M, Heinssen RK. Comprehensive Versus Usual Community Care for First-Episode 
Psychosis: 2-Year Outcomes From the NIMH RAISE Early Treatment Program. Am J Psychiatry. 2016;173:362-372. [PubMed: 26481174]

8. Marshall M, Lewis S, Lockwood A, Drake R, Jones P, Croudace T. Association between duration of untreated psychosis and outcome in cohorts of first-episode patients: a systematic review. Arch Gen Psychiatry. 2005;62:975-983. [PubMed: 16143729]

9. Wyatt RJ. Neuroleptics and the natural course of schizophrenia. Schizophr Bull. 1991;17:325-351. [PubMed: 1679255]

10. Lisman JE, Coyle JT, Green RW, Javitt DC, Benes FM, Heckers S, Grace AA. Circuit-based framework for understanding neurotransmitter and risk gene interactions in schizophrenia. Trends Neurosci. 2008;31:234-242. [PubMed: 18395805]

11. Olney JW, Farber NB. Glutamate receptor dysfunction and schizophrenia. Arch Gen Psychiatry. 1995;52:998-1007. [PubMed: 7492260]

12. Olney JW, Wozniak DF, Jevtovic-Todorovic V, Farber NB, Bittigau P, Ikonomidou C. Druginduced apoptotic neurodegeneration in the developing brain. Brain Pathol. 2002;12:488-498. [PubMed: 12408236]

13. Simantov R, Blinder E, Ratovitski T, Tauber M, Gabbay M, Porat S. Dopamine-induced apoptosis in human neuronal cells: inhibition by nucleic acids antisense to the dopamine transporter. Neuroscience. 1996;74:39-50. [PubMed: 8843076]

14. Keshavan MS, Haas GL, Kahn CE, Aguilar E, Dick EL, Schooler NR, Sweeney JA, Pettegrew JW. Superior temporal gyrus and the course of early schizophrenia: progressive, static, or reversible? J Psychiatr Res. 1998;32:161-167. [PubMed: 9793869]

15. Anderson KK, Voineskos A, Mulsant BH, George TP, McKenzie KJ. The role of untreated psychosis in neurodegeneration: a review of hypothesized mechanisms of neurotoxicity in firstepisode psychosis. Can J Psychiatry. 2014;59:513-517. [PubMed: 25565683]

16. Goff DC, Zeng B, Ardekani BA, Diminich ED, Tang Y, Fan X, Galatzer-Levy I, Li C, Troxel AB, Wang J. Association of Hippocampal Atrophy With Duration of Untreated Psychosis and Molecular Biomarkers During Initial Antipsychotic Treatment of First-Episode Psychosis. JAMA Psychiatry. 2018;75:370-378. [PubMed: 29466532]

17. Guo X, Li J, Wei Q, Fan X, Kennedy DN, Shen Y, Chen H, Zhao J. Duration of untreated psychosis is associated with temporal and occipitotemporal gray matter volume decrease in treatment naive schizophrenia. PLoS One. 2013;8:e83679. [PubMed: 24391807]

18. Malla AK, Bodnar M, Joober R, Lepage M. Duration of untreated psychosis is associated with orbital-frontal grey matter volume reductions in first episode psychosis. Schizophr Res. 2011;125:13-20. [PubMed: 21059482]

19. Rapp C, Canela C, Studerus E, Walter A, Aston J, Borgwardt S, Riecher-Rossler A. Duration of untreated psychosis/illness and brain volume changes in early psychosis. Psychiatry Res. 2017;255:332-337. [PubMed: 28601717]

20. Lee SW, Lee A, Choi TK, Kim B, Lee KS, Bang M, Lee SH. White matter abnormalities of the tapetum and their associations with duration of untreated psychosis and symptom severity in firstepisode psychosis. Schizophr Res. 2018;201:437-438. [PubMed: 29895415]

21. Manivannan A, Foran W, Jalbrzikowski M, Murty VP, Haas GL, Tarcijonas G, Luna B, Sarpal DK. Association Between Duration of Untreated Psychosis and Frontostriatal Connectivity During Maintenance of Visuospatial Working Memory. Biol Psychiatry Cogn Neurosci Neuroimaging. 2019.

22. Sarpal DK, Robinson DG, Fales C, Lencz T, Argyelan M, Karlsgodt KH, Gallego JA, John M, Kane JM, Szeszko PR, Malhotra AK. Relationship between Duration of Untreated Psychosis and Intrinsic Corticostriatal Connectivity in Patients with Early Phase Schizophrenia. Neuropsychopharmacology. 2017;42:2214-2221. [PubMed: 28294137]

23. Galinska B, Szulc A, Tarasow E, Kubas B, Dzienis W, Czernikiewicz A, Walecki J. Duration of untreated psychosis and proton magnetic resonance spectroscopy (1H-MRS) findings in firstepisode schizophrenia. Med Sci Monit. 2009;15:CR82-88. [PubMed: 19179972]

24. Anderson KK, Rodrigues M, Mann K, Voineskos A, Mulsant BH, George TP, McKenzie KJ. Minimal evidence that untreated psychosis damages brain structures: a systematic review. Schizophr Res. 2015;162:222-233. [PubMed: 25649287] 
25. Chakos MH, Lieberman JA, Bilder RM, Borenstein M, Lerner G, Bogerts B, Wu H, Kinon B, Ashtari M. Increase in caudate nuclei volumes of first-episode schizophrenic patients taking antipsychotic drugs. Am J Psychiatry. 1994;151:1430-1436. [PubMed: 7916539]

26. Navari S, Dazzan P. Do antipsychotic drugs affect brain structure? A systematic and critical review of MRI findings. Psychol Med. 2009;39:1763-1777. [PubMed: 19338710]

27. Hadley JA, Kraguljac NV, White DM, Ver Hoef L, Tabora J, Lahti AC. Change in brain network topology as a function of treatment response in schizophrenia: a longitudinal resting-state fMRI study using graph theory. NPJ Schizophr. 2016;2:16014. [PubMed: 27336056]

28. Kraguljac NV, White DM, Hadley JA, Visscher K, Knight D, ver Hoef L, Falola B, Lahti AC. Abnormalities in large scale functional networks in unmedicated patients with schizophrenia and effects of risperidone. Neuroimage Clin. 2016;10:146-158. [PubMed: 26793436]

29. Menon V Large-scale brain networks and psychopathology: a unifying triple network model. Trends Cogn Sci. 2011;15:483-506. [PubMed: 21908230]

30. Brandl F, Avram M, Weise B, Shang J, Simoes B, Bertram T, Hoffmann Ayala D, Penzel N, Gursel DA, Bauml J, Wohlschlager AM, Vukadinovic Z, Koutsouleris N, Leucht S, Sorg C. Specific Substantial Dysconnectivity in Schizophrenia: A Transdiagnostic Multimodal Meta-analysis of Resting-State Functional and Structural Magnetic Resonance Imaging Studies. Biol Psychiatry. 2019;85:573-583. [PubMed: 30691673]

31. Glahn DC, Ragland JD, Abramoff A, Barrett J, Laird AR, Bearden CE, Velligan DI. Beyond hypofrontality: a quantitative meta-analysis of functional neuroimaging studies of working memory in schizophrenia. Hum Brain Mapp. 2005;25:60-69. [PubMed: 15846819]

32. Gallego JA, Robinson DG, Sevy SM, Napolitano B, McCormack J, Lesser ML, Kane JM. Time to treatment response in first-episode schizophrenia: should acute treatment trials last several months? J Clin Psychiatry. 2011;72:1691-1696. [PubMed: 21939612]

33. Overall JE, Gorham DR. The brief psychiatric rating scale. Psychol Rep. 1962;10:799-812.

34. Randolph C, Tierney MC, Mohr E, Chase TN. The Repeatable Battery for the Assessment of Neuropsychological Status (RBANS): preliminary clinical validity. J Clin Exp Neuropsychol. 1998;20:310-319. [PubMed: 9845158]

35. Fischl B, Sereno MI, Dale AM. Cortical surface-based analysis. II: Inflation, flattening, and a surface-based coordinate system. Neuroimage. 1999;9:195-207. [PubMed: 9931269]

36. Dale AM, Fischl B, Sereno MI. Cortical surface-based analysis. I. Segmentation and surface reconstruction. Neuroimage. 1999;9:179-194. [PubMed: 9931268]

37. Smith SM, Jenkinson M, Woolrich MW, Beckmann CF, Behrens TE, Johansen-Berg H, Bannister PR, De Luca M, Drobnjak I, Flitney DE, Niazy RK, Saunders J, Vickers J, Zhang Y, De Stefano N, Brady JM, Matthews PM. Advances in functional and structural MR image analysis and implementation as FSL. Neuroimage. 2004;23 Suppl 1:S208-219. [PubMed: 15501092]

38. Desikan RS, Segonne F, Fischl B, Quinn BT, Dickerson BC, Blacker D, Buckner RL, Dale AM, Maguire RP, Hyman BT, Albert MS, Killiany RJ. An automated labeling system for subdividing the human cerebral cortex on MRI scans into gyral based regions of interest. Neuroimage. 2006;31:968-980. [PubMed: 16530430]

39. Klapwijk ET, van de Kamp F, van der Meulen M, Peters S, Wierenga LM. Qoala-T: A supervisedlearning tool for quality control of FreeSurfer segmented MRI data. Neuroimage. 2019;189:116129. [PubMed: 30633965]

40. Whitfield-Gabrieli S, Nieto-Castanon A. Conn: a functional connectivity toolbox for correlated and anticorrelated brain networks. Brain Connect. 2012;2:125-141. [PubMed: 22642651]

41. Glasser MF, Sotiropoulos SN, Wilson JA, Coalson TS, Fischl B, Andersson JL, Xu J, Jbabdi S, Webster M, Polimeni JR, Van Essen DC, Jenkinson M, Consortium WU-MH. The minimal preprocessing pipelines for the Human Connectome Project. Neuroimage. 2013;80:105-124. [PubMed: 23668970]

42. Power JD, Mitra A, Laumann TO, Snyder AZ, Schlaggar BL, Petersen SE. Methods to detect, characterize, and remove motion artifact in resting state fMRI. Neuroimage. 2014;84:320-341. [PubMed: 23994314]

43. Yeo BT, Krienen FM, Sepulcre J, Sabuncu MR, Lashkari D, Hollinshead M, Roffman JL, Smoller JW, Zollei L, Polimeni JR, Fischl B, Liu H, Buckner RL. The organization of the human cerebral 
cortex estimated by intrinsic functional connectivity. J Neurophysiol. 2011;106:1125-1165. [PubMed: 21653723]

44. Judd CM, Kenny DA. Process analysis estimating mediation in treatment evaluations. Eval Rev. 1981;5:602-608.

45. Panizzon MS, Fennema-Notestine C, Eyler LT, Jernigan TL, Prom-Wormley E, Neale M, Jacobson K, Lyons MJ, Grant MD, Franz CE, Xian H, Tsuang M, Fischl B, Seidman L, Dale A, Kremen WS. Distinct genetic influences on cortical surface area and cortical thickness. Cereb Cortex. 2009;19:2728-2735. [PubMed: 19299253]

46. Wierenga LM, Langen M, Oranje B, Durston S. Unique developmental trajectories of cortical thickness and surface area. Neuroimage. 2014;87:120-126. [PubMed: 24246495]

47. Rakic P Defects of neuronal migration and the pathogenesis of cortical malformations. Prog Brain Res. 1988;73:15-37. [PubMed: 3047794]

48. Casanova MF. Schizophrenia seen as a deficit in the modulation of cortical minicolumns by monoaminergic systems. International Review of Psychiatry. 2009;4:361-372.

49. Glausier JR, Lewis DA. Dendritic spine pathology in schizophrenia. Neuroscience. 2013;251:90107. [PubMed: 22546337]

50. Raghanti MA, Spocter MA, Butti C, Hof PR, Sherwood CC. A comparative perspective on minicolumns and inhibitory GABAergic interneurons in the neocortex. Front Neuroanat. 2010;4:3. [PubMed: 20161991]

51. Sweet RA, Bergen SE, Sun Z, Sampson AR, Pierri JN, Lewis DA. Pyramidal cell size reduction in schizophrenia: evidence for involvement of auditory feedforward circuits. Biol Psychiatry. 2004;55:1128-1137. [PubMed: 15184031]

52. Bernstein HG, Steiner J, Guest PC, Dobrowolny H, Bogerts B. Glial cells as key players in schizophrenia pathology: recent insights and concepts of therapy. Schizophr Res. 2015;161:4-18. [PubMed: 24948484]

53. Korschenhausen DA, Hampel HJ, Ackenheil M, Penning R, Muller N. Fibrin degradation products in post mortem brain tissue of schizophrenics: a possible marker for underlying inflammatory processes. Schizophr Res. 1996;19:103-109. [PubMed: 8789908]

54. Muller N, Schwarz M. Schizophrenia as an inflammation-mediated dysbalance of glutamatergic neurotransmission. Neurotox Res. 2006;10:131-148. [PubMed: 17062375]

55. Muller N, Weidinger E, Leitner B, Schwarz MJ. The role of inflammation in schizophrenia. Front Neurosci. 2015;9:372. [PubMed: 26539073]

56. Pasternak O, Westin CF, Bouix S, Seidman LJ, Goldstein JM, Woo TU, Petryshen TL, MesholamGately RI, McCarley RW, Kikinis R, Shenton ME, Kubicki M. Excessive extracellular volume reveals a neurodegenerative pattern in schizophrenia onset. J Neurosci. 2012;32:17365-17372. [PubMed: 23197727]

57. Kelly C, de Zubicaray G, Di Martino A, Copland DA, Reiss PT, Klein DF, Castellanos FX, Milham MP, McMahon K. L-dopa modulates functional connectivity in striatal cognitive and motor networks: a double-blind placebo-controlled study. J Neurosci. 2009;29:7364-7378. [PubMed: 19494158]

58. Nagano-Saito A, Liu J, Doyon J, Dagher A. Dopamine modulates default mode network deactivation in elderly individuals during the Tower of London task. Neurosci Lett. 2009;458:1-5. [PubMed: 19442867]

59. Argyelan M, Carbon M, Ghilardi MF, Feigin A, Mattis P, Tang C, Dhawan V, Eidelberg D. Dopaminergic suppression of brain deactivation responses during sequence learning. J Neurosci. 2008;28:10687-10695. [PubMed: 18923044]

60. Tomasi D, Volkow ND, Wang GJ, Wang R, Telang F, Caparelli EC, Wong C, Jayne M, Fowler JS. Methylphenidate enhances brain activation and deactivation responses to visual attention and working memory tasks in healthy controls. Neuroimage. 2011;54:3101-3110. [PubMed: 21029780]

61. Tomasi D, Volkow ND, Wang R, Telang F, Wang GJ, Chang L, Ernst T, Fowler JS. Dopamine transporters in striatum correlate with deactivation in the default mode network during visuospatial attention. PLoS One. 2009;4:e6102. [PubMed: 19564918] 
62. Liu B, Song M, Li J, Liu Y, Li K, Yu C, Jiang T. Prefrontal-related functional connectivities within the default network are modulated by COMT val158met in healthy young adults. J Neurosci. 2010;30:64-69. [PubMed: 20053888]

63. Hadley JA, Nenert R, Kraguljac NV, Bolding MS, White DM, Skidmore FM, Visscher KM, Lahti AC. Ventral tegmental area/midbrain functional connectivity and response to antipsychotic medication in schizophrenia. Neuropsychopharmacology. 2014;39:1020-1030. [PubMed: 24165885]

64. Doucet GE, Moser DA, Luber MJ, Leibu E, Frangou S. Baseline brain structural and functional predictors of clinical outcome in the early course of schizophrenia. Mol Psychiatry. 2018.

65. Bora E, Yalincetin B, Akdede BB, Alptekin K. Duration of untreated psychosis and neurocognition in first-episode psychosis: A meta-analysis. Schizophr Res. 2018;193:3-10. [PubMed: 28634088]

66. Bora E Differences in cognitive impairment between schizophrenia and bipolar disorder: Considering the role of heterogeneity. Psychiatry Clin Neurosci. 2016;70:424-433. [PubMed: 27233969]

67. Register-Brown K, Hong LE. Reliability and validity of methods for measuring the duration of untreated psychosis: a quantitative review and meta-analysis. Schizophr Res. 2014;160:20-26. [PubMed: 25464915] 

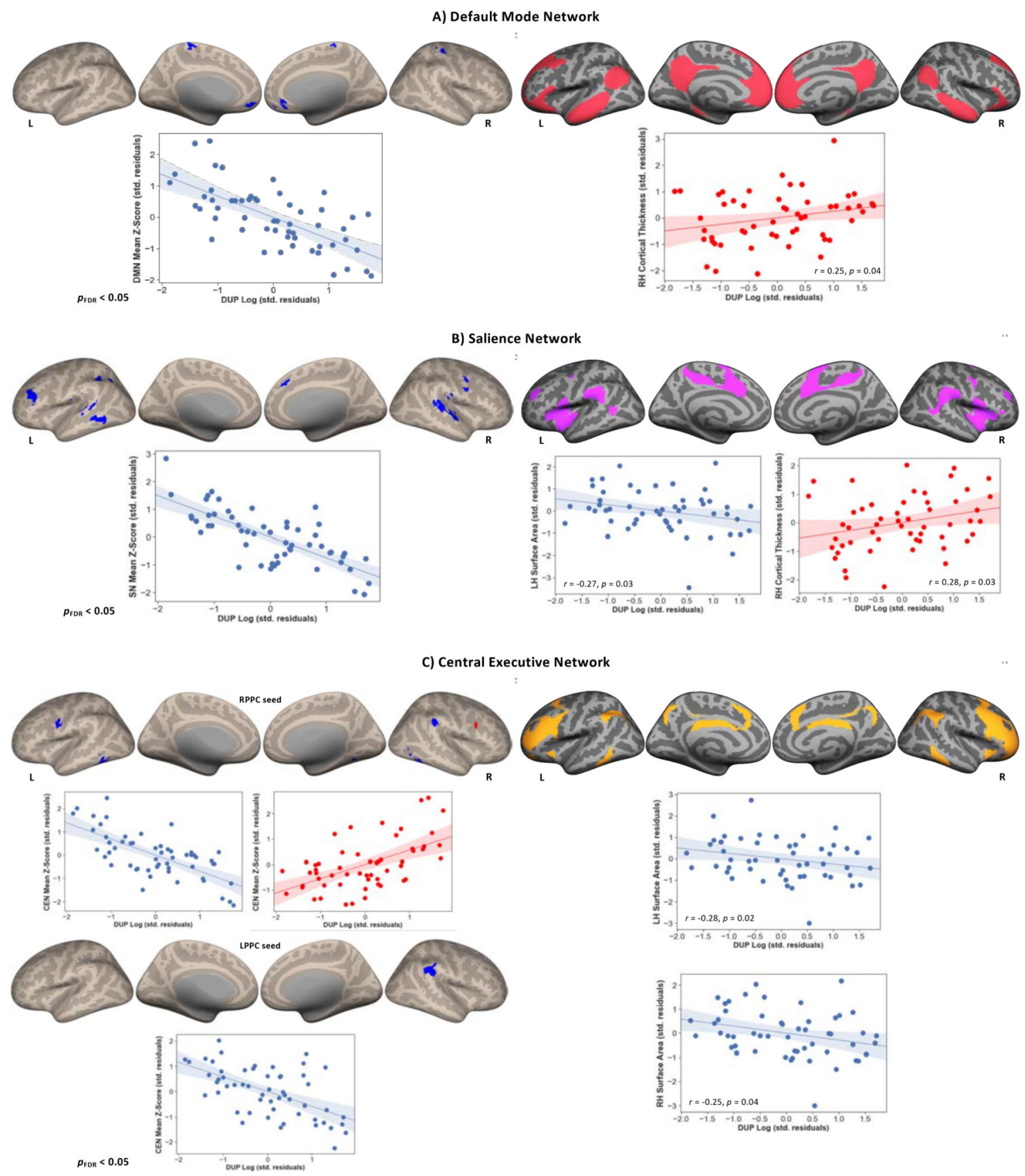

Figure 1.

Clusters of significant partial correlations between DUP with FC $\left(p_{\mathrm{FDR}}<0.05\right.$,) and masks rendered on the fsaverage brain used for brain morphology analyses and partial correlation plots for A) default mode, B) salience, and C) central executive network. For FC-DUP correlations, signal from all clusters were averaged and plotted with DUP for data visualization purposes. All data are standardized residuals from controlling for age, gender, and intracranial volume (morphological analyses). 


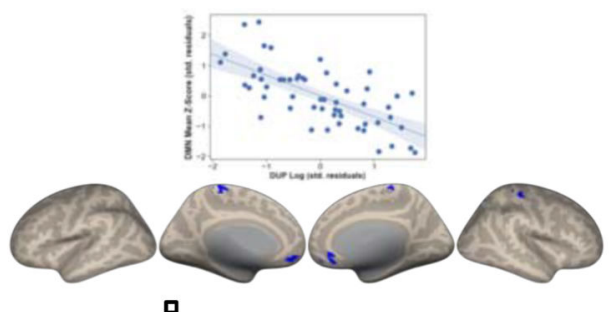

口 FC DMN

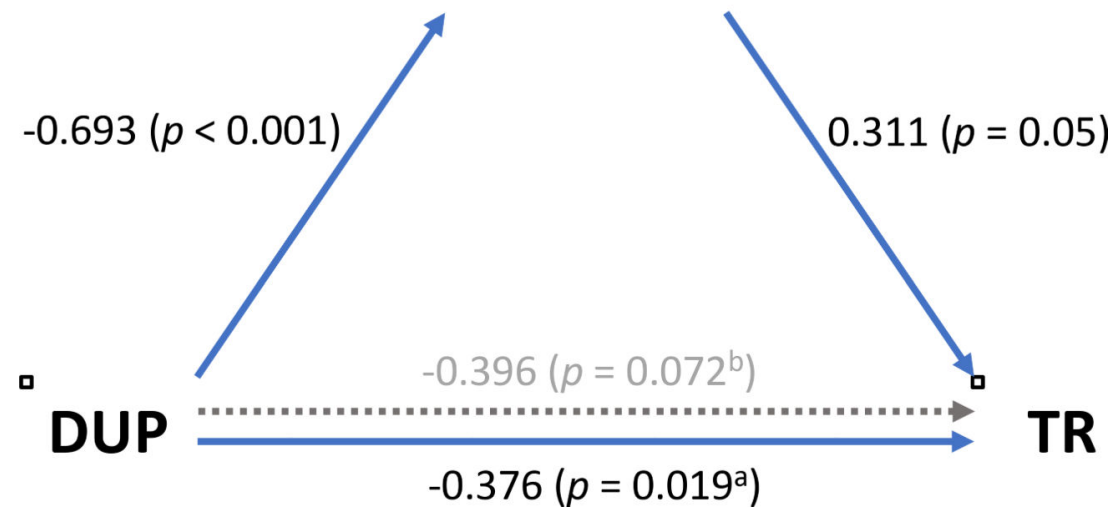

Figure 2.

aDUP significantly predicts TR; ${ }^{\mathrm{b}}$ when FC DMN is added to the model, DUP no longer predicts TR (Sobel test $[z=-1.94, p=0.03]$ ). DUP = duration of untreated psychosis; $\mathrm{TR}=$ treatment response; FC DMN = signal from significant clusters from Figure 1A. 
Table 1.

Demographics, clinical measures, and data quality

\begin{tabular}{|c|c|}
\hline & $\mathbf{N}=\mathbf{5 5}$ \\
\hline \multicolumn{2}{|l|}{ Demographic variables } \\
\hline Age (in years) & $24.18 \pm 6.27(14-40)$ \\
\hline Sex $(\%$ male $)$ & $64 \%$ \\
\hline Parental occupation & $5.91 \pm 4.83(1-18)$ \\
\hline No. of Cannabis users (\%) & $31 \%$ \\
\hline No. of Smokers (\%) & $42 \%$ \\
\hline Smocking (Packs p/day) & $0.22 \pm 0.34(0-1)$ \\
\hline \multicolumn{2}{|l|}{ Clinical Variables } \\
\hline \multicolumn{2}{|l|}{ Diagnosis } \\
\hline Schizophrenia & 27 \\
\hline Schizoaffective Disorder & 11 \\
\hline Bipolar disorder with Psychosis & 3 \\
\hline Schizophreniform Disorder & 2 \\
\hline Psychosis NOS & 10 \\
\hline Brief psychotic disorder & 1 \\
\hline Major Depressive Disorder w/psychosis & 1 \\
\hline DUP (in months) & $19.65 \pm 39.42(0.5-180)$ \\
\hline${ }^{a}$ Treatment Response (\%) & $60.43 \pm 21.06(9-82)$ \\
\hline \multicolumn{2}{|l|}{$b_{\text {BPRS Baseline }}$} \\
\hline Total & $51.4 \pm 11.99(32-84)$ \\
\hline Positive & $11.74 \pm 3.55(3-20)$ \\
\hline Negative & $6.23 \pm 3.38(3-16)$ \\
\hline \multicolumn{2}{|l|}{$c_{\text {BPRS Week } 16}$} \\
\hline Total & $29.56 \pm 5.82(20-45)$ \\
\hline Positive & $4.44 \pm 1.91(3-10)$ \\
\hline Negative & $5.53 \pm 2.49(3-12)$ \\
\hline Risperidone dose at Week 16 (in mg) & $4.76 \pm 2.42(1-8)$ \\
\hline \multicolumn{2}{|l|}{$d_{\text {RBANS }}$} \\
\hline Total index & $75.67 \pm 15.04(50-117)$ \\
\hline Immediate Memory & $83.02 \pm 18.37(44-123)$ \\
\hline Visuospatial/Constructional & $76.40+17.20(50-121)$ \\
\hline Language & $83.73 \pm 16.21(40-112)$ \\
\hline Attention & $81.56 \pm 16.38(43-109)$ \\
\hline Delayed Memory & $79.69 \pm 13.26(40-102)$ \\
\hline \multicolumn{2}{|l|}{ Scan Quality Data } \\
\hline No. (\%) of volumes after scrubbing & $93.77 \pm 6.97(70-100)$ \\
\hline Framewise displacement (in mm) & $0.32 \pm 0.19(0.11-0.89)$ \\
\hline
\end{tabular}

Notes: Value \pm standard deviation (range); data available for 
$a_{48}$ patients

$b_{53 \text { patients }}$

$c_{43}$ patients

$d_{41 \text { patients }}$

RBANS $=$ Repeatable Battery for the Assessment of Neuropsychological Status; BPRS $=$ Brief Psychiatric Rating Scale; DUP = Duration of Untreated Psychosis. 
Table 2.

Regions Exhibiting Significant Correlations between FC and DUP, Separately for DMN, SN, and CEN.

\begin{tabular}{|c|c|c|c|c|c|c|}
\hline \multirow[b]{2}{*}{ Seed (Network) } & \multirow[b]{2}{*}{ Location, Hemisphere } & \multicolumn{3}{|c|}{ MNI Coordinates } & \multirow{2}{*}{ Cluster size (voxels) } & \multirow[b]{2}{*}{$R^{2}$} \\
\hline & & $\mathbf{x}$ & $\mathbf{y}$ & $\mathbf{z}$ & & \\
\hline \multicolumn{7}{|l|}{ PCC (DMN) } \\
\hline & Frontal Medial Cortex & -12 & 42 & -12 & 196 & 0.35 \\
\hline & Precentral Gyrus, L & -2 & -32 & 68 & 132 & 0.25 \\
\hline & Postcentral Gyrus, R & 36 & -28 & 64 & 124 & 0.25 \\
\hline \multicolumn{7}{|l|}{ RAI (SN) } \\
\hline & Planum Temporale, $\mathrm{R}$ & 64 & -32 & 8 & 530 & 0.39 \\
\hline & Middle Temporal Gyrus, L & -60 & -46 & -4 & 313 & 0.41 \\
\hline & Middle Frontal Gyrus, L & -38 & 32 & 22 & 197 & 0.41 \\
\hline & Supramarginal Gyrus, L & -42 & -46 & 40 & 173 & 0.28 \\
\hline & Precentral Gyrus, L & 52 & 2 & 44 & 129 & 0.31 \\
\hline & Lateral Occipital Cortex, L & -30 & -64 & 56 & 118 & 0.29 \\
\hline & Planum Temporale, L & -60 & -26 & 10 & 111 & 0.28 \\
\hline & Paracingulate Gyrus, L & 4 & 28 & 32 & 97 & 0.28 \\
\hline \multicolumn{7}{|l|}{ RPPC (CEN) } \\
\hline & Supramarginal Gyrus, R & 54 & -40 & 36 & 165 & 0.31 \\
\hline & Inferior temporal gyrus, $\mathrm{L}$ & -48 & -52 & -12 & 141 & 0.28 \\
\hline & Temporal Occipital, R & 32 & -56 & -10 & 136 & 0.38 \\
\hline & Precentral Gyrus, L & -58 & 4 & 34 & 115 & 0.33 \\
\hline & Middle Frontal Gyrus, R & 48 & 16 & 34 & 112 & 0.31 \\
\hline \multicolumn{7}{|l|}{ LPPC (CEN) } \\
\hline & Supramarginal Gyrus, R & 66 & -38 & 28 & 372 & 0.33 \\
\hline
\end{tabular}

Abbreviations: PCC, posterior cingulate cortex; RAI, right anterior insula; PPC, posterior parietal cortex; L, left; R, right; Exec., executive. 
Table 3.

Correlations between DUP and brain morphology, Separately for DMN, SN, and CEN.

\begin{tabular}{ccccccccc}
\hline Network & \multicolumn{2}{c}{ Surface Area } & \multicolumn{2}{c}{ Cortical Thickness } & \multicolumn{2}{c}{ Volume } \\
\hline & Left & Right & & Left & Right & & Left & Right \\
\cline { 2 - 3 } DMN & $-0.21^{*}$ & $-0.21^{*}$ & 0.17 & $0.25^{* * *}$ & -0.11 & -0.05 \\
SN & $-0.27^{* *}$ & $-0.23^{*}$ & 0.15 & $0.28^{* *}$ & -0.18 & -0.08 \\
CEN & $-0.25^{* *}$ & $-0.28^{* *}$ & $0.20^{*}$ & $0.22^{*}$ & -0.14 & -0.12 \\
\hline
\end{tabular}

All correlations are controlled for age and intracranial volume

* $<<0.1$

*** $\mathrm{p}<0.05$

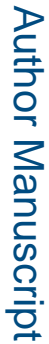

$\mathrm{N}=53$ 